\title{
DESAFIOS E POSSIBILIDADES DOS CURSOS DE EXTENSÃO PARA A FORMAÇÃO CONTINUADA DE PROFESSORES DE LÍNGUA PORTUGUESA NA PERSPECTIVA DA LINGUÍSTICA APLICADA ${ }^{1}$
}

\author{
MiLene BAZARIM \\ Universidade Federal de Campina Grande (UFCG), Campina Grande, PB, Brasil / \\ Universidade Católica de Pernambuco (UNICAP), Recife, PE, Brasil \\ MARIA Augusta Gonçalves de MACEDo ReInALDO \\ Universidade Federal de Campina Grande (UFCG), Campina Grande, PB, Brasil
}

\begin{abstract}
Resumo: O objetivo deste artigo é apresentar os desafios e possibilidades inerentes à realização de cursos de extensão para a formação continuada de professores de Língua Portuguesa. Esta pesquisa se insere no campo aplicado de estudos de linguagem, fundamentando-se teoricamente, sobretudo, nas concepções do interacionismo sociodiscursivo. Do ponto de vista metodológico, trata-se de uma pesquisa qualitativa do tipo estudo de caso. Os resultados mostram que as atividades, discussões e reflexões fomentadas nos cursos de extensão podem propiciar reconfigurações relevantes nos modos de pensar e agir de professores em formação continuada em serviço a respeito do uso da sequência didática de gênero textual como um instrumento didático. No entanto, a gestão do tempo/espaço escolar no planejamento de atividades que contemplem, articulada e equanimemente, os eixos de uso (leitura, escrita e oralidade) e de reflexão sobre a língua (análise linguística) continua sendo um desafio.
\end{abstract}

Palavras-chave: Ação de extensão; Formação continuada; Sequência didática. Gênero textual.

\section{INTRODUÇÃO}

No Brasil, a partir da década de 1990, com a publicação dos Parâmetros Curriculares Nacionais - PCN (BRASIL, 1998), o conceito de gênero textual/discursivo foi amplamente difundido, desencadeando as possibilidades e os desafios inerentes à eleição do gênero textual como organizador do processo de ensino e aprendizagem de Língua Portuguesa (LP) na Educação Básica.

Duas décadas depois, no entanto, continuam relevantes estudos sobre a relação entre as pesquisas sobre os gêneros textuais e seu ensino, problematizando o lugar dos gêneros nas aulas de LP. A nosso ver, as razões para a relevância de se continuar estudando essa relação são aquelas apontadas por Miranda (2015): a existência de diferentes perspectivas de descrição que sustentam o trabalho de ensino de LP, a partir de gêneros textuais, significa a coexistência de concepções e posicionamentos diversos 
sobre esse objeto; a presença saliente dos gêneros no ensino de LP não tem sido garantia de trabalhos fundamentados em pressupostos claros; a ênfase dada aos gêneros gerou uma fuga do ensino da gramática, causando desequilíbrio entre o estudo da diversidade textual e o estudo do componente linguístico dos gêneros.

$O$ estudo aqui apresentado surgiu, portanto, da necessidade de se continuar pesquisando sobre o ensino de LP, a partir de gêneros textuais, a fim de realizar a correlação de conhecimentos já produzidos sobre a descrição de gêneros e as demandas para a didatização adequada às exigências dos contextos diversificados de ensino na pós-modernidade. Dessa forma, tomou como objeto de estudo a relação entre atividades didáticas, enfoques de gênero que lhes dão sustentação e implicações para o exercício do docente de LP.

Especificamente, as ações realizadas na pesquisa concentraram-se nas ações formativas - cursos de extensão - que contemplassem as diferentes dimensões, a flexibilidade e a variação dos gêneros enquanto objeto de estudo e megainstrumento para o ensino, bem como na identificação e reflexão sobre os possíveis efeitos dessas ações na prática dos professores em formação continuada.

Após esta breve introdução, são apresentados, neste artigo, os fundamentos teóricos que embasaram as ações formativas, realizadas sob a forma de curso de extensão; segue-se a seção de fundamentos metodológicos, na qual discutimos questões relacionadas à pesquisa qualitativa e descrevemos o contexto de geração e/ou coleta dos registros analisados; na quarta e quinta seções, são apresentados e discutidos, respectivamente, os desafios das ações formativas e as reconfigurações no pensar e no agir de uma professora participante; encerrando o artigo, há algumas considerações finais e as referências.

\section{A ABORDAGEM INTERACIONISTA SOCIODISCURSIVA (ISD) DE GÊNERO TEXTUAL: ENFOQUE ANALÍTICO E DIDÁTICO}

Assumimos na pesquisa e, por conseguinte, neste artigo, a abordagem interacionista sociodiscursiva, considerando os seus avanços no campo da engenharia didática para a Educação Básica. Os estudos situados nessa abordagem compreendem o gênero de texto como formato de ações comunicativas globais (COUTINHO, 2007) e defendem um modelo de análise fundamentado na ideia de que, para a produção de um texto, são necessárias representações de uma situação social, que pode ser descrita por um conjunto de parâmetros físicos (emissor, receptor, espaço-tempo do ato de produção) e sociossubjetivos (tipo de interação social em curso, objetivos possíveis nesse quadro, papéis atribuídos aos protagonistas da interação) (BRONCKART, 1999).

A preocupação dessa tendência teórica com o ensino de língua levou os estudiosos a proporem um modelo para o ensino da produção de textos orais e escritos a partir de gêneros com base em dois instrumentos que relacionam os parâmetros, citados acima, com a configuração textual: o modelo didático de gênero (MDG), que evidencia as dimensões ensináveis do texto (DE PIETRO; SCHNEUWLY, 2003), e a sequência didática (SD), conjunto de atividades escolares organizadas, de maneira sistemática, em torno de um gênero textual, oral ou escrito (DOLZ; NOVERRAZ; 
SCHNEUWLY, 2004). Ambos os instrumentos sobressaem no Brasil pelas contribuições dadas à sistematização das práticas docentes.

O MDG consiste na descrição de características dos gêneros, organizadas para serem exploradas em ações educativas. Esse modelo é elaborado a partir dos estudos existentes sobre os gêneros em referência, abrangendo a identificação e a caracterização de dimensões ensináveis relativas a três níveis de descrição: 1) a situação comunicativa, também chamada de ação de linguagem, a organização interna global do texto, levando-se em conta a infraestrutura (que comporta a planificação geral do conteúdo e a organização dos tipos de discurso); 2) a configuração textual, os mecanismos de textualização (que contribuem para dar ao texto a coerência temática, por meio dos mecanismos de conexão e de coesão nominal e verbal); e 3) os mecanismos de responsabilização enunciativa, que contribuem para a coerência pragmática do texto através do textualizador, instância a que o autor empírico confia a responsabilidade sobre o que enuncia, por meio da distribuição das vozes e da modalização (BRONCKART, 1999).

Estudos brasileiros têm reconhecido a importância da base teórica para as adaptações necessárias em cada contexto de ensino, o que permite construir atividades de ensino/aprendizagem diversas para um mesmo público-alvo (MACHADO; CRISTÓVÃO, 2006; CARNIN; ALMEIDA, 2015). Como esses estudiosos, entendemos o MDG como uma construção que procura estabelecer um modelo de referência, e não de regras, para o trabalho adequado do professor, contemplando as características que precisam ser definidas para a modelização do gênero selecionado.

Já a SDG, conjunto de atividades organizadas a partir de um gênero textual, objetiva propiciar ao aluno o desenvolvimento das capacidades de linguagem necessárias à produção de um determinado gênero oral ou escrito. As capacidades de linguagem têm sido objeto de estudo e ampliação no âmbito do ISD. Assim, inicialmente em número de três, foram descritas a capacidade de ação, que diz respeito à habilidade de produzir um texto adequado ao contexto de produção e ao conteúdo temático de um determinado gênero textual; a capacidade discursiva, que se refere à habilidade de mobilização de modelos discursivos e da infraestrutura geral adequados à arquitetura interna dos textos de um determinado gênero textual; e a capacidade linguístico-discursiva, que se refere à habilidade de mobilização de mecanismos de textualização e de responsabilização enunciativa adequados à arquitetura interna do textos de um determinado gênero textual (DOLZ; SCHNEUWLY, 2004). Posteriormente, Cristovão e Stutz (2011) criaram as capacidades de significação, que se referem ao aspecto ideológico e do sentido mais amplo da atividade de linguagem. Mais recentemente, Dolz (2015), refletindo sobre os aspectos multimodais dos textos, criou cinco capacidades multissemióticas (CMS), caracterizadas da seguinte forma: compreender as relações de sentido entre elementos verbais e não verbais do gênero (1CMS); apreender os diferentes conhecimentos e sentidos que emergem de sons, vídeos e imagens (2CMS); reconhecer a importância de elementos não verbais para a construção de sentidos (3CMS); relacionar elementos não verbais com o contexto social macro que o cerca (4CMS); compreender os elementos semióticos na constituição do gênero (5CMS).

A SDG, embora tenha apresentado resultados positivos para o ensino de LP a partir de gêneros textuais, sobretudo no início da década de 2000 (CORDEIRO; 
AZEVEDO; MATTOS, 2004; GUIMARÃES, 2006), também apresentou lacunas e insuficiências. O que levou os pesquisadores brasileiros a proporem ampliações teóricometodológicas, motivados pelas características próprias de nosso sistema de ensino, pelas condições socioeducacionais e pelas práticas de letramento de nossos alunos.

Nesse sentido, têm sido propostas alterações no âmbito dos procedimentos que configuram a estrutura de base da SD, com a inclusão de módulos antes da produção inicial do texto, no estudo dos problemas detectados nessa produção inicial e após a produção final (REINALDO; BEZERRA, 2019). Essas alterações da SD para contemplar atividades de reconhecimento do gênero e de leitura já são ratificadas por Swiderski e Costa Hübes (2009), conforme figura a seguir.

Figura 1. (Re)configuração do esquema da sequência didática

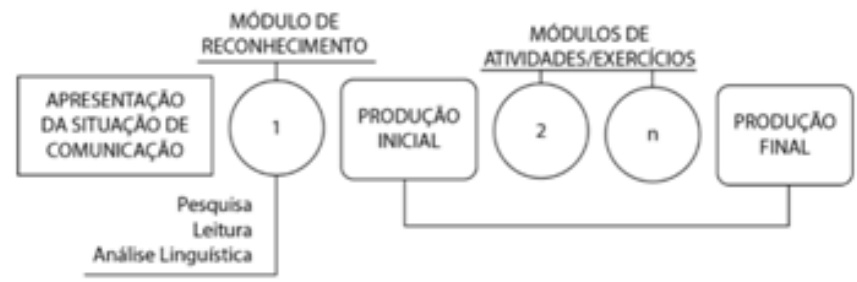

Fonte: Swiderski e Costa-Hübes (2009, p. 120)

A adaptação da SD feita por Swiderski e Costa-Hübes (2009) para atender às necessidades de contexto educacional brasileiro, não a desvincula teoricamente do procedimento proposto pelo grupo genebrino, tendo em vista que um gênero textual continua sendo o organizador das atividades dos módulos. Pensando não somente nessa ampliação, mas, sobretudo, no caráter central do gênero textual, como o desencadeador das atividades, nas ações e publicações realizadas no âmbito da nossa pesquisa, preferimos utilizar o termo sequência didática de gênero textual (SDG), em vez de apenas sequência didática (SD).

\section{FUNDAMENTOS METODOLÓGICOS}

A pesquisa cujos resultados estão sendo apresentados neste artigo se insere na interface entre o campo de investigação sobre formação, profissionalização docente e práticas educativas, e o campo de investigações da Linguística Aplicada (LA). Assim como Pennycook (2006), definimos e defendemos uma LA transgressiva, "como uma abordagem mutável e dinâmica para as questões da linguagem em contextos múltiplos, em vez de como um método, uma série de técnicas, ou um corpo fixo de conhecimento" (PENNYCOOK, 2006, p. 68). Logo, a LA transgressiva consiste em um modo de pensar e fazer sempre problematizador na construção de objetos de pesquisa híbridos, complexos e dinâmicos.

As investigações realizadas no âmbito da LA que aderem a essa concepção utilizam metodologias de base qualitativo-interpretativista, como o estudo de caso. 
Além de ser sensível à complexidade do real e de admitir a transdisciplinaridade, o uso do estudo de caso, neste trabalho, possibilitou uma análise em profundidade do evento estudado, e as pesquisadoras não ficaram atreladas a um determinado protocolo de pesquisa, estando atentas aos imprevistos, aos intempestivos, às relações moventes e ao novo (PALMA FILHO, 2004; SIGNORINI, 1998).

Tendo em vista que "cada caso é tratado como tendo um valor intrínseco" (LÜDKE; ANDRÉ, 1986, p. 21), a possibilidade de generalização passa a ter menor relevância, pois o interesse se volta para a investigação sistemática de uma instância específica. Quanto à generalização do que foi apreendido para outros contextos semelhantes, isso dependerá do tipo de leitor ou do usuário do estudo (LÜDKE E ANDRÉ, 1986, p. 23). Assim, o conhecimento gerado pelo estudo de caso é mais concreto, contextualizado e voltado para a interpretação do leitor (ANDRÉ, 2005, p. 17).

Neste artigo, o foco da análise envolveu apenas os registros gerados em contexto de formação continuada em serviço, compreendendo não só as práticas formativas que ocorrem justapostas à experiência do ofício, no horário e no local de trabalho, mas também as que se dão independentemente do horário e local. As últimas organizam as suas ações enfatizando a otimização do trabalho docente, intervindo nele de forma indireta (mudança de concepções que apontam para mudanças na prática) ou direta (intervenções realizadas no contexto de sala de aula).

Apesar de, no decorrer da pesquisa, terem sido realizadas três ações extensionistas ${ }^{2}$, neste artigo são apresentados os resultados da análise dos registros referentes à primeira ação, o curso de extensão: "Didatização de Gêneros Textuais no Ensino Fundamental", realizado em 2016, com 90 horas (dois módulos de 45h).

Nas pesquisas realizadas no campo de estudos da LA, procura-se construir objetos de pesquisa de natureza multifacetada e complexa. Por essa razão, não é seguido um percurso de investigação que obedeça a um "programa fixo pré-montado", mas um "plano" sempre orientado para as "regularidades locais" e para as "relações moventes" (SIGNORINI, 1998, p. 102-103). O objetivo é manter a "especificidade", o "novo" e o "complexo" como elementos constituintes do objeto selecionado. Assim, as pesquisas que, como esta, são realizadas no campo de estudos da LA, reconhecem, mesmo não explicitamente, que no processo de análise sempre haverá reduções. Por não se adotar um percurso analítico linear, da observação às conclusões, e por se considerar que a retroação é um movimento necessário, torna-se impossível estabelecer uma divisão estanque entre a observação, a classificação e a elaboração de conclusões. Sempre são necessárias várias idas e vindas dos registros às hipóteses, das hipóteses aos registros.

Nas seções a seguir, apresentamos e discutimos os resultados da análise, que remetem ao processo de ensino e aprendizagem no contexto de formação continuada de professores de LP acima mencionado.

\section{DESAFIOS ENFRENTADOS NAS AÇÕES FORMATIVAS}

A formação continuada em serviço, por meio dos cursos de extensão, precisou enfrentar vários desafios, da disponibilidade de horário das professoras em atuação na Educação Básica até a falta de incentivo da própria instituição de ensino superior (IES). Antes mesmo que os desafios da didatização do gênero fossem identificados, a equipe 
se surpreendeu com o resultado da atividade para diagnóstico aplicada às cursistas no primeiro encontro. Ao revelarem as suas dificuldades/necessidades, elas apontaram a gestão de sala de aula (interação professor-aluno; a pouca motivação dos alunos para aprender; indisciplina, entre outros) como a principal dificuldade enfrentada no processo de didatização. Esse quadro motivou uma reconfiguração inicial do curso, com o objetivo de encorajar as professoras a permanecerem na formação continuada.

Para isso, acreditando na influência das múltiplas linguagens e das diversas tecnologias na educação, integramos à ação formativa a exibição e discussão do filme "Escritores de Liberdade", bem como do vídeo feito pelo Prof. Dr. Emerson Arruda sobre - tema "Educar para a construção de valores" (disponível em: https://www.youtube.com/watch?v=6xXxiXOciHQ ).

Com essa iniciativa, foi possível refletir sobre o impacto da realidade (incluindo mundos de letramento) dos alunos no processo de didatização, mas também buscar formas para se (re)conhecer, compreender e considerar essa realidade no processo de didatização.

No âmbito da didatização, como em qualquer ação de formação continuada de professores, o primeiro desafio envolveu a tensão entre a solidarização e a sobreposição de saberes ${ }^{3}$, já cristalizados nas e pelas práticas escolares de ensino, e os saberes advindos de pesquisas acadêmicas que aderem a diferentes pressupostos teóricometodológicos. De forma mais específica, o desafio enfrentado foi a articulação entre tema e gênero textual. Como a ação de extensão foi realizada em parceria com a Secretaria Municipal de Educação (SEDUC) de Campina Grande, tornou-se necessária a escolha de um gênero, entre os elencados nas orientações curriculares do município para cada ano do Ensino Fundamental, a partir do qual pudesse também ser abordado o tema, já previamente definido, "Direitos humanos: construindo valores, vivenciando a cidadania". Por conta dessa prescrição, percebemos que houve muita dificuldade entre as cursistas na escolha de um gênero textual e, posteriormente, na seleção de textos empíricos do gênero adequados à zona de desenvolvimento proximal dos alunos de suas turmas. Essa etapa foi desafiadora também porque foi necessária a solidarização entre os (novos) saberes apresentados pelas pesquisadoras no curso e os já estabilizados no sistema municipal de ensino.

Posteriormente, foi possível perceber que a dificuldade na definição de um gênero textual como organizador das atividades da SDG estava relacionada também ao pouco conhecimento das cursistas em atuação sobre os gêneros a serem didatizados. Esse quadro se tornou um desafio ainda maior quando as formadoras perceberam a ausência de descrição dos gêneros textuais (modelo didático de gênero) escolhidos pelas professoras cursistas, à luz das categorias analíticas do ISD, possíveis de serem compartilhadas no contexto de formação continuada em serviço. Essa é uma dificuldade, que corresponde ao segundo desafio, recorrente no processo de didatização, conforme observam Machado e Cristovão (2006, p. 554):

O que temos observado, nas diferentes reformas levadas a cabo, é que aqueles especializados em ensino de línguas têm sido obrigados, no primeiro nível da transposição, a se servirem de elementos provenientes de diferentes teorias ou de diferentes subáreas, tentando construir um mínimo 
BAZARIM, M.; REINALDO, M. A. C. de M.

de coerência no próprio campo didático, que, infelizmente, nem sempre pode ser atingida.

As ações de extensão tinham como objetivo primordial minimizar algumas dificuldades na didatização de gêneros textuais realizada por professores/as em atuação nos anos finais do Ensino Fundamental. Como a inscrição do/as professores/as ficou a cargo da SEDUC, a equipe também se surpreendeu ao perceber que a maioria das professoras cursistas atuava nos anos iniciais. Com isso, surgiu o terceiro desafio, pois, no acervo do projeto, não havia exemplos de SDG aplicadas em turmas dos anos iniciais. Dessa forma, as formadoras, membros do grupo de pesquisa, tiveram que contar com o auxílio das próprias cursistas para a adequação das atividades exemplificadas ao contexto dos alunos dos anos iniciais do Ensino Fundamental.

O quarto desafio enfrentado pelas formadoras para convencer as cursistas da possibilidade de elaboração e implementação da SDG, proposta por Swiderski e Costa Hübes (2009), foram as restrições do tempo/espaço, os quais, na escola são fragmentados e compartimentalizados em ano e dias letivos, bimestres e aulas. Há local, data e duração previamente estabelecidas para a realização das atividades, o que deve ser considerado durante o planejamento. Nesse sentido, acaba sendo compreensível a dificuldade para a articulação entre leitura, análise linguística e produção de texto a partir de um gênero textual.

Por fim, superar o foco da alfabetização na decodificação, bem como a crença de que alunos nos anos iniciais, sobretudo no primeiro ano, não são capazes de produzir textos constituiu o quinto desafio, o qual está diretamente associado à dificuldade na articulação entre atividades de leitura, análise linguística e escrita de forma a garantir a continuidade e progressão das atividades da SDG mantendo a unidade de gênero textual.

\section{RECONFIGURAÇÕES NOS MODOS DE PENSAR E AGIR DE UMA PROFESSORA CURSISTA}

As ações de extensão realizadas no âmbito da pesquisa apresentaram-se também como possibilidades para a construção de uma ponte entre universidade e escola, o que pode significar tanto a otimização e dinamização da formação continuada dos professores em atuação quanto da formação inicial dos licenciandos. Para ilustrar um caso de dinamização da formação continuada nas ações formativas desenvolvidas, apresentamos e refletimos, nesta seção, sobre as reconfigurações identificadas nos modos de pensar e agir de uma professora cursista.

A professora colaboradora, cujos registros foram analisados, possui mais de 20 anos de experiência profissional, é graduada em Pedagogia, especialista em Educação Infantil e em Supervisão e Orientação Educação e, em 2013, concluiu o Mestrado Profissional em formação de professores. A escolha dessa professora como colaboradora da pesquisa considerou a sua assiduidade, interesse e participação durante o curso. Além disso, ela enviou todas as atividades solicitadas pelas formadoras, bem como recebeu uma das pesquisadoras da equipe em sua sala de aula para acompanhar a aplicação de algumas das atividades da SDG.

Para Zabala (1998, p. 18-23), a constituição das sequências de atividades é uma das possibilidades de se determinar as características diferenciais da prática educativa, 
entendida, neste trabalho, como prática de ensino. Em relação à reconfiguração do trabalho docente, estamos aderindo ao posicionamento de Meira (2018), para quem "o trabalho docente é algo que pode ser reconfigurado pela linguagem e na linguagem na medida em que os professores refletem e buscam responder às inquietações advindas do seu 'métier"' (MEIRA, 2018, p. 18). Com isso, todo professor, ao tentar superar as dificuldades, os desafios e as necessidades no cotidiano das escolas, pode alterar os modos de pensar e de agir, dando uma nova configuração ao seu trabalho.

As reconfigurações no modo de pensar da professora colaboradora correspondem a mudanças de concepções, crenças e/ou valores que subjazem, consciente ou inconscientemente, seus modos de agir na avaliação, no planejamento do processo de ensino-aprendizagem e na aula. Como em uma reação em cadeia, mudanças nas concepções, crenças e/ou valores sobre o uso da SDG nos anos iniciais, para otimizarem, de fato, o processo de ensino em busca de melhores resultados de aprendizagem, precisam provocar também mudanças nos modos de agir, primeiramente no que diz respeito ao planejamento das atividades de ensino.

Nesta pesquisa, foram os textos das duas versões da atividade para diagnóstico, da atividade de autoavaliação, do plano de ensino, das atividades da SDG e do artigo acadêmico elaborado pela professora, pontos de um processo sempre em fluxo, que é o da (re)construção de conhecimentos, que apontaram para as reconfigurações nos modos de pensar e agir da professora colaboradora. Tais reconfigurações foram suscitadas principalmente pelas atividades, discussões e reflexões realizadas durante $o$ curso de extensão.

No primeiro encontro do curso de extensão, foi feita a seguinte solicitação: "A partir de pesquisas na internet ${ }^{4}$ sobre o tema 'Direitos humanos: construindo valores, vivenciando a cidadania', selecione um exemplar de um gênero textual e elabore uma atividade com questões que integrem leitura, escrita e análise linguística. Sua atividade deverá ser enviada como anexo para o e-mail". Para a realização dessa atividade, foram disponibilizadas duas horas e meia. A partir dela, a equipe de pesquisadoras formadoras pôde identificar as principais necessidades de aprendizagem dos participantes e (re)ver o planejamento do curso. A seguir, apresentamos a atividade realizada pela professora colaboradora.

Figura 2. Atividade elaborada pela professora colaboradora

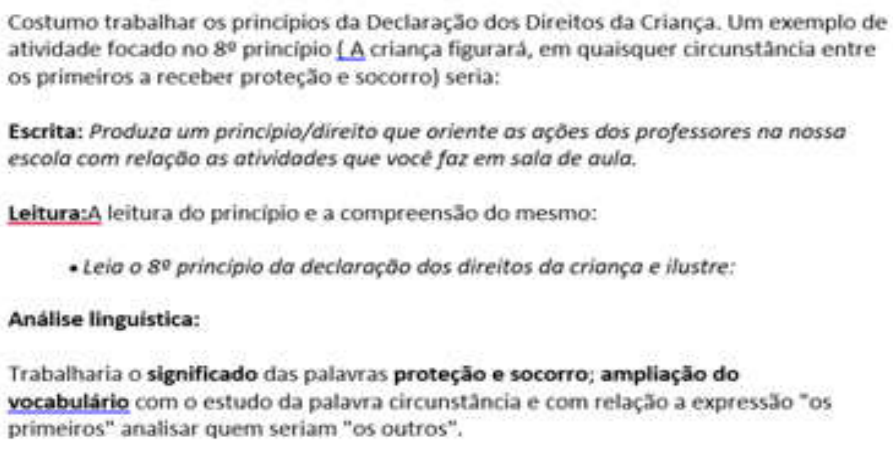


Fonte: Acervo do curso de extensão

Conforme a Figura 2, é possível perceber que a professora colaboradora não elabora uma atividade a ser aplicada aos alunos, condição essa ausente no comando de produção, mas uma espécie de plano de uma atividade. Todavia, fica evidente a tentativa de articulação entre o tema e um gênero textual e entre os eixos de uso (leitura e escrita) e reflexão (análise linguística) sobre a língua. A escolha do gênero textual "Declaração dos Direitos da Criança" foi surpreendente. Embora houvesse pertinência em relação ao tema, esse não parecia o gênero mais adequado a alunos de uma turma de $1^{\circ}$ ano. A possibilidade de a própria professora colaboradora ter desconfiado da inadequação do texto empírico e do gênero escolhido está no fato de a atividade a ser realizada concentrar-se apenas em um fragmento da declaração ( $8^{\circ}$ princípio).

O trabalho com fragmentos de textos empíricos de qualquer gênero textual não é endossado nem pelo ISD nem pelas demais teorias que abordam o processo de ensino-aprendizagem da leitura e da escrita a partir da concepção interacional da língua/gem. Além disso, a ordem das atividades propostas também não encontra respaldo em propostas de SDG orientadas pelos princípios do grupo genebrino, pois a solicitação de produção da escrita é feita antes que a situação de comunicação seja apresentada ao aluno. Apesar disso, foi possível perceber que a professora colaboradora já não submete os alunos do primeiro ano a tarefas completamente descontextualizadas, mecânicas, repetitivas e com rigoroso controle vocabular, que caracterizam práticas de ensino da escrita em uma perspectiva tradicional de alfabetização. Sobretudo no que diz respeito à análise linguística, a preocupação central é com a construção de sentidos de duas palavras-chave do $8^{\circ}$ princípio: proteção e socorro.

Por atender às solicitações das cursistas em relação à gestão de sala de aula e ao tema, a reflexão, bem como a reescrita dessa atividade, só foi feita no oitavo encontro, conforme a Figura 3, a seguir.

Figura 3. Questões para análise e reflexão da atividade 1

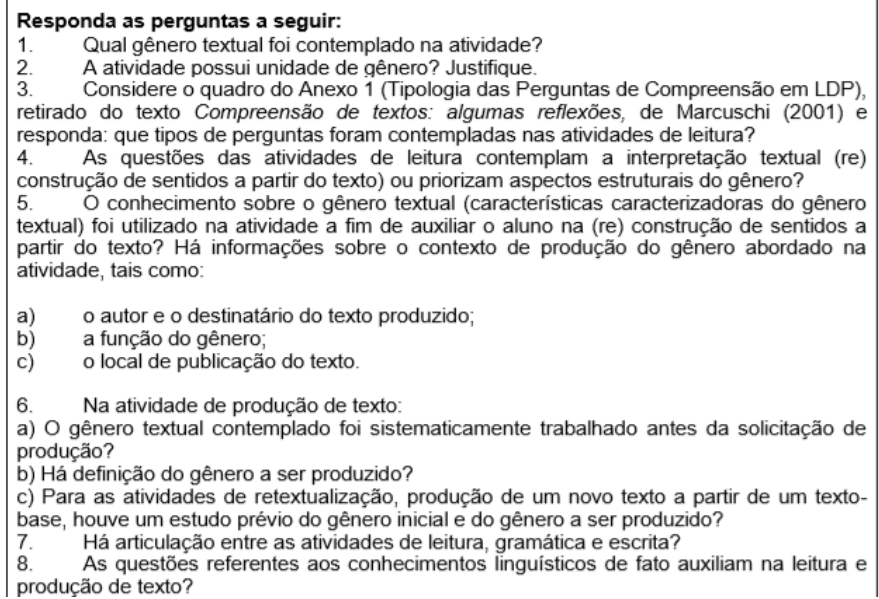

Fonte: Acervo do curso de extensão e Meira (2018, p. 52) 
As perguntas para análise e reflexão (Figura 3) propostas pelo curso abordam aspectos relevantes para a construção de atividades de uma SDG à luz dos preceitos do ISD, entre eles a manutenção da unidade de gênero textual e a realização de tarefas que desenvolvam as capacidades de linguagem. As atividades de uma SDG contemplam diferentes textos empíricos, os quais, geralmente, pertencem a um único gênero textual. Dessa forma, é possível garantir a sistematização, a continuidade e progressão das atividades da SDG. Isso, todavia, não significa que textos empíricos de outros gêneros não possam ser utilizados no processo, apenas que o foco das atividades e, por conseguinte da aprendizagem, reside em um gênero.

Nessa perspectiva, as questões propostas nessa atividade de análise e reflexão funcionaram como um andaime no qual a professora colaboradora pôde se apoiar para reconfigurar sua forma de pensar e de agir. Na sua análise, a professora relata:

Trecho 1

Percebi que não produzi questões referentes à leitura, compreensão e interpretação do gênero e sim tão somente pedi a leitura de parte (no caso 1 princípio) da declaração. $O$ que me levou a pensar numa atividade tão elementar é o nível da turma e a necessidade inicial da compreensão do texto. Poderia ter ampliado a atividade, elaborando após a leitura do princípio e representação de sua compreensão através do desenho, questões objetivas para ratificar a compreensão incluindo questões envolvendo o vocabulário. Ao produzir as questões daria ênfase à compreensão dos princípios e não a estrutura da declaração. Daria essa informação para conhecimento do gênero, não para a apreensão, [...] fiz um recorte do gênero, mas costumo trabalhar todos os princípios, inclusive exemplificando o contexto de utilidade dos mesmos. (Trecho citado por Meira, 2018, p. 53)

Esse trecho demonstra a reconfiguração da professora no seu modo de pensar, pois ela reconhece a inadequação do uso de fragmentos de um texto empírico do gênero textual e a ausência, na atividade elaborada, de tarefas que propiciassem a compreensão do princípio lido. Essa reconfiguração foi essencial na (re)elaboração da atividade exemplificada na Figura 4, a seguir. 
BAZARIM, M.; REINALDO, M. A. C. de M.

Figura 4. Versão final da atividade para diagnóstico dos alunos

Escola Municipal xxxxx
Campina Grande,

8-Do quê Cascão tem medo?

9- Na tirinha de $n^{\circ} 1$ Cascão pedia Socorro nos dois primeiros quadrinhos. O motivo é o mesmo?

10-Que fenômeno climático acontece na tirinha?

11-O que aconteceu no último quadrinho?

11-A ajuda de Cebolinha no terceiro quadrinho deixou Cascão agradecido por quê?

12- Se você fosse contar essa história a alguém, como você faria?

Fonte: Acervo do curso de extensão

Como é perceptível e bastante comum, a primeira versão da atividade, Figura 2, produzida no primeiro encontro com função diagnóstica, foi completamente abandonada. Na versão final, Figura 4, não é feito um plano de atividade, mas uma atividade que não só poderia, como foi aplicada na turma do primeiro ano. Além disso, a professora colaboradora seleciona outro gênero textual, a tirinha, que parece mais

Inter-Ação, Goiânia, v.46, n.1, p. 391-408, jan./mar. 2021. Disponível em: <http://dx.doi.org/10.5216/ia.v45i3.65131>. 
adequado à zona de desenvolvimento proximal de alunos do primeiro ano e também permite abordagem das capacidades multissemióticas; utiliza o texto empírico do gênero selecionado completo e não um fragmento; atende e transcende ao comando de produção do curso, construindo questões que contemplam não só a ampliação da competência leitora, mas também propiciam o (re)conhecimento de algumas características do gênero textual abordado.

Das 12 questões, quatro contemplaram a identificação de informação (verbal e não verbal) explícita (2, 7, 10 e 11); uma contemplou a avaliação (12); duas possibilitaram a ativação de conhecimento prévio (1 e 3); cinco requereram inferências (4, 5, 6, 8 e 11). Isso demonstra que a professora não adere à concepção de leitura somente como decodificação, algo ainda muito comum em atividades realizadas em turmas dos anos iniciais. Já em relação ao desenvolvimento das capacidades de linguagem, por meio de três questões, é possível que os alunos ampliem a capacidade de ação, pois elas apontam para o contexto de produção/recepção do texto empírico gênero $(2,3)$ e para o conteúdo temático (7), bem como a capacidade discursiva e linguístico-discursiva, já que as questões 4 e 6 abordam a arquitetura interna do texto, contemplando, inclusive, aspectos multissemióticos.

Todas essas alterações apontam para reconfigurações no modo de agir da professora colaboradora também em sala de aula. Como esse movimento de retorno das atividades para reflexão foi constante no âmbito do curso de extensão, tornaram-se evidentes novas reconfigurações nos modos de pensar, os quais foram registrados tanto nos relatos feitos sobre a aplicação das atividades quanto no artigo escrito pela professora colaboradora. Com isso, identificamos reconfigurações nos modos de pensar sobre a avaliação, sobre a didatização de gêneros textuais e sobre a possibilidade de elaboração e aplicação de uma SDG em turmas dos anos iniciais do ensino fundamental.

Os trechos exemplificados a seguir demonstram reconfigurações em relação ao efeito de reversibilidade dos resultados da atividade diagnóstica na elaboração de um plano de ensino e das atividades de uma SDG.

Trecho 2

a partir da aplicação e correção da atividade [para diagnóstico] verificamos o grau de conhecimento e maturidade da criança, a respeito do gênero a ser trabalhado e a compreensão leitora do mesmo. Percebemos nessa atividade que, questões relativas a estrutura composicional do gênero, 0 conhecimento dos suportes textuais a função social da tirinha, as marcas gráficas e icônicas imprescindíveis para a compreensão da quadrinização, assim como a ordem sequencial dos quadrinhos para leitura, se constituíam em conhecimentos que deveriam ser trabalhados pois as crianças demonstraram compreensão equivocada ou inexistente sobre esses assuntos. (Trecho do artigo produzido pela professora colaboradora)

Trecho 3

A execução da sequência didática e o êxito obtido, verificado através de sucessivas avaliações, feitas concomitantes a execução da SD, evidenciou o 
BAZARIM, M.; REINALDO, M. A. C. de M.

quão positivo foi o acompanhamento avaliativo sistemático e progressivo a cada etapa trabalhada da sequência, demostrando um desenvolvimento progressivo nas aprendizagens. (Trecho do artigo produzido pela professora colaboradora)

Conforme o preconizado em Bazarim (2019), por meio desses trechos é possível perceber que o ato de avaliar passa a ser concebido pela professora colaboradora como um componente da prática pedagógica, isto é, essencial na elaboração e implementação das atividades da SDG.

A seguir, apresentamos um trecho em que fica evidente a reconfiguração dos modos de pensar da professora colaboradora quanto à didatização de gênero textual.

Trecho 4

Com relação aos processos de transposição didática dos gêneros, percebemos a importância de priorizar a qualidade versus quantidade de gêneros trabalhados, pois, importa abordar tanto a leitura, escrita, como análise linguística destes e isso demanda tempo. (Trecho do artigo produzido pela professora colaboradora)

Devido ao fato de a SEDUC encaminhar uma lista de conteúdos, entre eles os gêneros textuais a serem abordados em cada um dos quatro bimestres do ano letivo, havia, entre as professoras cursistas, a concepção de que todos os gêneros sugeridos para cada bimestre precisariam ser contemplados. Aderindo ao modelo de SDG proposto por Swiderski e Costa Hübes (2009), as atividades, discussões e reflexões fomentadas nos encontros do curso, propiciaram a reconfiguração desse modo de pensar e, consequentemente, de agir.

No trecho a seguir, é possível verificar a reconfiguração do modo de conceber a SDG como organizadora do trabalho docente.

Trecho 5

As conclusões desse trabalho são parciais, pois outras sequências didáticas serão elaboradas com uso das etapas da construção do plano de ensino, a atividade diagnóstica para trabalharmos as dificuldades na compreensão leitora e na estrutura composicional do gênero, assim como o trabalho com as três dimensões da linguagem a saber: leitura, escrita e análise linguística. (Trecho do artigo produzido pela professora colaboradora)

Nesse exemplo, a professora sinaliza que aderiu à SDG como organizadora de sua prática de ensino ao mencionar que "outras sequências didáticas serão elaboradas", demonstrando que se apropriou das discussões e reflexões realizadas no âmbito do curso de extensão. Tais reconfigurações, embora muito positivas, não eliminam os desafios, apresentados e discutidos na seção anterior.

\section{CONSIDERAÇÕES FINAIS}

Com base nas reflexões realizadas no âmbito deste artigo, constatamos que, apesar dos desafios, os cursos de extensão podem constituir uma alternativa promissora de oferta de formação continuada em serviço. Na ação extensionista focalizada neste 
artigo, percebemos que há o (re)conhecimento, por parte de uma das cursistas em formação continuada, sobre a concepção de gênero textual como um megainstrumento no ensino de LP. No entanto, permanece a dificuldade em relação às diferentes abordagens teóricas do gênero e em relação ao processo de didatização, principalmente na articulação com a análise linguística.

Isso provavelmente se deve ao fato de que ainda prevalece no contexto investigado uma concepção tradicional e tecnicista de currículo, na qual ele é entendido como lista de conteúdos somente conceituais a serem transmitidos aos alunos nas aulas. Dessa forma, o gênero textual tem sido transformado em um conteúdo meramente conceitual e não em uma ação de linguagem cujas capacidades possam ser desenvolvidas no contexto da aula de LP.

No decorrer do curso, verificamos que há também o (re)conhecimento por parte dos professores em atuação que participaram da extensão da necessidade de construção de uma prática de formação continuada em serviço como um locus que privilegie as necessidades reais do trabalho docente. Assim, consideramos que a parceria entre as instituições de ensino superior (IES) e os sistemas de ensino na oferta de cursos de extensão pode ser uma alternativa para a implementação, de fato, de uma política de formação continuada em serviço.

Para isso, contudo, seria necessário estar atento a alguns princípios: 1) a formação em serviço deve acontecer de forma contínua e articulada; 2) a participação na formação em serviço precisa ser considerada uma atribuição dos professores, devendo ocorrer durante o seu horário de trabalho; 3 ) a formação em serviço deve estar atrelada às metas e aos objetivos estabelecidos no Plano Municipal e/ou Estadual de Educação; e 4) a formação em serviço deve ser realizada com a colaboração das instituições formadoras (IES).

Entendemos, por fim, que para contribuir, de forma efetiva, tanto com os professores de LP já em atuação quanto com os licenciandos, a formação continuada em serviço com a parceria das IES precisa se constituir como uma via de mão dupla, provocando reconfiguração não só nas práticas escolares de ensino da $L P$, mas, principalmente, nas práticas de formação dos professores que irão atuar na Educação Básica. Dessa forma, não são apenas os saberes escolares sobre processo de ensinoaprendizagem, didatização, gênero textual, escrita, entre outros, que precisam estar sujeitos à modificação, mas também aqueles que são divulgados pelas próprias IES. Nesse sentido, os discursos e/ou saberes aos quais as IES aderem deixariam de ser uma força centrípeta e passariam a atuar como uma força centrífuga, repercutindo de forma mais favorável na qualidade do ensino de LP da escola pública brasileira.

Artigo recebido em: 19/08/2020

Aprovado para publicação em: 18/11/2020

CHALLENGES AND POSSIBILITIES OF EXTENSION COURSES IN THE CONTINUING EDUCATION OF PORTUGUESE LANGUAGE TEACHERS IN THE PERSPECTIVE OF APPLIED LINGUISTICS 
BAZARIM, M.; REINALDO, M. A. C. de M.

ABSTRACT: The objective of this article is to present the results of a research that contemplated the challenges and possibilities inherent to the realization of extension courses for the continuous training of Portuguese Language teachers. This research is inserted in the applied field of language studies, based theoretically, above all, in the conceptions of sociodiscursive interactionism (SDI). From a methodological point of view, this is a qualitative case study. The results point out that the activities, discussions and reflections fostered in the extension courses can provide relevant reconfigurations in the ways of thinking and acting of teachers in continuing education in service regarding the use of the didactic sequence of gender as a didactic instrument, however, the management of school time / space in planning activities that articulate and equanimously contemplate the axes of use (reading, writing and speaking) and reflection on the language (linguistic analysis) remains a challenge.

KEYWORDS: Extension. Continuing Education. Didactic Sequence. Textual Genre. DESAFÍOS Y POSIBILIDADES DE LOS CURSOS DE EXTENSIÓN EN LA EDUCACIÓN CONTINUA DE
PROFESORES DE LENGUA PORTUGUESA DESDE LA PERSPECTIVA DE LA LINGÜÍSTICA APLICADA

RESUMEN: El objetivo de este artículo es el de presentar los resultados de una investigación que contempló los desafíos inherentes a la realización de cursos de extensión para la formación continua de profesores de portugués. Esta investigación se inserta en el campo aplicado de los estudios del lenguaje, basado teóricamente, sobre todo, en las concepciones del interaccionismo sociodiscursivo. Desde un punto de vista metodológico, es un estudio de caso cualitativo. Los resultados indican que las actividades, discusiones y reflexiones fomentadas en los cursos de extensión pueden proporcionar reconfiguraciones relevantes en las formas de pensar y actuar de los docentes en la educación continua activos con respecto al uso de la secuencia didáctica del género como instrumento didáctico. Sin embargo, la gestión del tiempo / espacio escolar en actividades de planificación que articulan y contemplan de manera ecuánime los ejes de uso (lectura, escritura y oralidad) y la reflexión sobre el idioma (análisis lingüístico) sigue siendo un desafío.

PALABRAS ClAVE: Extensión Académica. Educación Continua; Secuencia Didáctica. Género Textual.

\section{NOTAS}

1 - Este artigo resulta das reflexões desenvolvidas no Projeto de pesquisa "Gêneros textuais como objeto de ensino: perspectivas teóricas e instrumentos didáticos." (Plataforma Brasil CAAE No 6490118; Parecer 2.065.140), vinculado ao Grupo de Pesquisa "Teorias da linguagem e ensino" (Diretório dos Grupos de Pesquisa do Brasil - CNPq).

2 - Foram realizadas também as seguintes ações extensionistas: Programa de extensão "A didatização de gêneros textuais no Ensino Fundamental: da orientação à prática no Ensino de Língua Portuguesa", realizado em 2017, contemplando três cursos de 45 horas; curso de extensão "Didatização de Gêneros Textuais no Ensino Fundamental - ordem do narrar, contos de fadas", realizado em 2019, com carga horária de $15 \mathrm{~h}$. Tais ações foram realizadas em parceria com a Secretaria Municipal de Educação de Campina Grande - PB.

Inter-Ação, Goiânia, v.46, n.1, p. 391-408, jan./mar. 2021. Disponível em: <http://dx.doi.org/10.5216/ia.v45i3.65131>. 
3 - Em sua pesquisa, Rafael (2001) identificou dois efeitos na transposição didática dos conceitos advindos da linguística textual para a sala de aula: a solidarização e a sobreposição. A solidarização pode ser definida como efeito de conjunção, aglutinação ou compatibilização entre os saberes. Já a sobreposição, ocorre quando são estabelecidas equivalências não procedentes entre saberes.

4 - Salientamos que os encontros formativos eram realizados em um laboratório de informática, no qual os computadores estavam conectados à internet.

\section{REFERÊNCIAS}

BAZARIM, M. O ato de avaliar como catalisador da inovação na formação de professores de língua portuguesa (LP). Travessias Interativas. v. 9, n. 19, 2019, p. 230-258. Disponível em: https://seer.ufs.br/index.php/Travessias/article/view/12692. Acesso em: 11 jan. 2020.

BRASIL. Secretaria de Ensino Fundamental. Parâmetros Curriculares Nacionais: Língua Portuguesa. Brasília: SEF/MEC, 1998.

BRONCKART, J. P. Atividade de linguagem, textos e discursos: por um interacionismo sociodiscursivo. São Paulo: Educ, 1999.

CARNIN, A.; ALMEIDA, A. P. Modelo(s) didático(s) de gênero: da concepção teórica à transposição didática na formação continuada de professores. In: GUIMARÃES, A. M. M.; CARNIN, A.; KERSCH, D. F (Orgs). Caminhos da construção: reflexões sobre projetos didáticos de gênero. Campinas, SP: Mercado das Letras, 2015, p. 29-46.

CORDEIRO, G.S.; AZEVEDO, I.C.M.; MATTOS, V.L. Trabalhando com sequências didáticas: uma proposta de ensino e de análise de narrativas de aventuras de viagens. Calidoscópio. v. 2, n. 1, 2004, p. 29-42. Disponível em: http://revistas.unisinos.br/index.php/calidoscopio/article/view/6479. Acesso em: 03 ago. $\underline{2020}$.

CRISTOVÃO, V. L. L.; STUTZ, L. Sequências didáticas: semelhanças e especificidades no contexto francófono como L1 e no contexto brasileiro como LE. In: SZUNDY, P. T.C.; ARAÚJO, J. C. de; NICOLAIDES, C. S. (Orgs.). Linguística aplicada e sociedade: ensino e aprendizagem de línguas no contexto brasileiro. Campinas, SP: Pontes, 2011, p. 17-39.

CRISTOVÃO, V. L. L. Para uma expansão do conceito de capacidades de linguagem. In: BUENO, L.; LOPES, M. A. P. T.; CRISTOVÃO, V. L. L. (Orgs.). Gêneros textuais e formação inicial: uma homenagem à Malu Matêncio. Campinas, SP: Mercado de Letras, 2013, p. 69-81.

COUTINHO, A. Descrever gêneros de texto: resistências e estratégias. Anais. 4\%. Simpósio Internacional de Estudos de Gêneros Textuais. v.1, 2007, p. 639-647.Disponível 
BAZARIM, M.; REINALDO, M. A. C. de M.

em: http://linguagem.unisul.br/paginas/ensino/pos/linguagem/eventos/cd/Port/20.pdf. Acesso em: 21 jan. 2020.

DE PIETRO, J. F.; SCHNEUWLY, B. Le modèle didactique du genre: un concept de l'ingénierie didactique. Recherches en didactiques. Les Cahiers Théodile, n. 3, 2003, p. 27-52. Disponível em: https://archive-ouverte.unige.ch/unige:32539. Acesso em: 28 mar. 2020.

DOLZ, J.; SCHNEUWLY, B. Gêneros e progressão em expressão oral e escrita - elementos para reflexões sobre uma experiência suiça (francófona). In: SCHNEUWLY, B.; DOLZ, J. (Org.). Gêneros orais e escritos na escola. Campinas, SP: Mercado de Letras, 2004, p. 41-70.

DOLZ, J.; NOVERRAZ, M.; SCHNEUWLY, B. Sequências didáticas para o oral e a escrita: apresentação de um procedimento. In: SCHNEUWLY, B.; DOLZ, J. (Org.). Gêneros orais e escritos na escola. Campinas, SP: Mercado de Letras, 2004, p. 95-128.

DOLZ, J. Seminário 2015 - Palestra Prof. Joaquim Dolz (1/3). 2015. Disponível em: https://www.youtube.com/watch?v=K68WLhlcSrc. Acesso em: 13 dez. 2017.

GUIMARÃES, A. M. de M. Construindo propostas de didatização de gênero: desafios e possibilidades. Linguagem em (Dis)curso, Tubarão, v. 6, n. 3, 2006, p. 347-374. Disponível em:

http://linguagem.unisul.br/paginas/ensino/pos/linquagem/linguagem-emdiscurso/0603/060301.pdf. Acesso em: 03 ago. 2020.

LUDKE, M.; ANDRÉ, M.E.D.A. Pesquisa em educação: abordagens qualitativas. São Paulo: EPU, 1986.

MACHADO, A. R.; CRISTÓVÃO, V. L. L. A construção de modelos didáticos de gêneros: aportes e questionamentos para o ensino de gêneros. Linguagem em (Dis)curso, v. 6 , n. $\quad 3, \quad 2006 . \quad$ p. 547-573. Disponível em: http://portaldeperiodicos.unisul.br/index.php/Linguagem_Discurso/article/view/349/37 0. Acesso em: 21 jan. 2020.

MEIRA, V. L. Didatização de gêneros textuais em contexto de formação continuada: reconfigurando atividades de leitura em propostas de SD. 2018. 83 f. Dissertação. (Mestrado em Linguagem e Ensino) - Unidade Acadêmica de Letras, Universidade Federal de Campina Grande, Campina Grande-PB. Disponível em: https://drive.google.com/file/d/10j4jnSW46zOEG5w42uqsxqbsY6w2lt8x/view. Acesso em: 12 jan. 2020.

MIRANDA, F. Considerações sobre o ensino de gêneros textuais: pesquisa e intervenção. In: MIRANDA, F.; LEURQUIN. E; COUTINHO, M. A. (org.) Formação docente: textos, teorias e práticas. Campinas, SP: Mercado de Letras, 2015, p. 217-240.

Inter-Ação, Goiânia, v.46, n.1, p. 391-408, jan./mar. 2021. Disponível em: <http://dx.doi.org/10.5216/ia.v45i3.65131> 
PALMA-FILHO, J.C. Estudo de caso. In: COELHO, J.G. et al. Pedagogia Cidadã: Cadernos de Formação: Metodologia de Pesquisa Científica e Educacional. São Paulo: UNESP, 2004, p. 123-126.

PENNYCOOK, A. Uma linguística aplicada transgressiva. In: MOITA-LOPES, L.P. Por uma linguística aplicada indisciplinar. São Paulo: Parábola, 2006, p. 67-84.

REINALDO, M.A; BEZERRA, M.A. Do conceito de sequência didática ao de projeto didático de gênero no âmbito do ensino de português - língua materna. Revista de Letras. v. 29, n. 58, 2019, p. 37-62. Disponível em: https://periodicos.ufsm.br/letras/article/view/34773. Acesso em: 28 mar. 2020.

SCHNEUWLY, B.; DOLZ, J. (Org.). Gêneros orais e escritos na escola. Campinas, SP: Mercado de Letras, 2004.

SIGNORINI, I. Do residual ao múltiplo e ao complexo: o objeto de pesquisa em linguística aplicada. In: SIGNORINI, I. ; CAVALCANTI, M.C. (Orgs.). Linguística Aplicada e transdisciplinaridade. Campinas-SP: Mercado de Letras, 1998, p. 99-111.

SWIDERSKY, R.M.S.; COSTA-HÜBES, T.C. Abordagem sociointeracionista \& sequência didática: relato de uma experiência. Línguas e Letras, Cascavel, v.10, n.18, 2009, p. 113$128 . \quad$ Disponível em: http://erevista.unioeste.br/index.php/linguaseletras/article/view/2253. Acesso em: 28 mar. 2020.

ZABALA, A. A prática educativa: unidades de análise. In: ZABALA, A. A prática educativa: como ensinar. Porto Alegre, Artmed, 1998, p. 13-26.

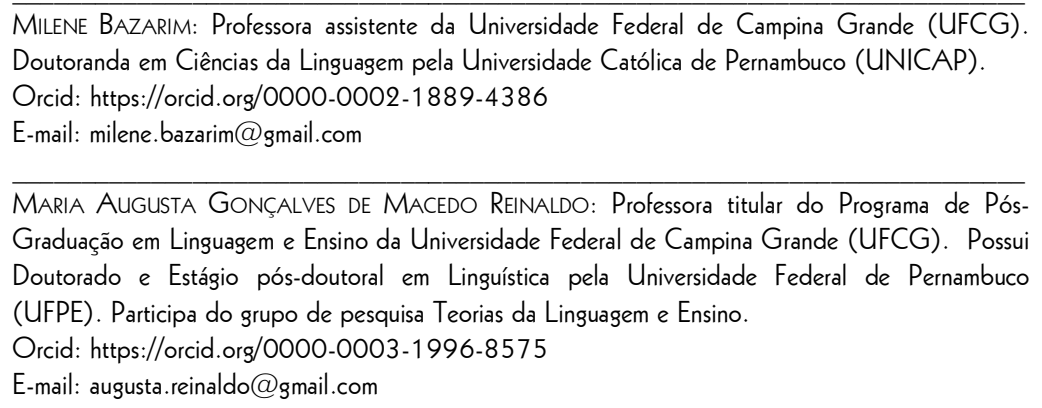

Este periódico utiliza a licença Creative Commons Attribution 3.0, para periódicos de acesso aberto (Open Archives Iniciative - OAI). 